\title{
INFORMATION SYSTEM SECURITY (CYBER SECURITY)
}

\author{
Muhammad Siddique Ansari \\ Software Engeneering \\ UTS (University of Technology Sydney) \\ 15 Broadway Ultimo NSW 2007 \\ Siddique_ansari23@hotmail.com
}

\begin{abstract}
Business Organizations and Government unequivocally relies on upon data to deal with their business operations. The most unfavorable impact on association is disappointment of friendship, goodness, trustworthiness, legitimacy and probability of data and administrations. There is an approach to ensure data and to deal with the IT framework's Security inside association. Each time the new innovation is made, it presents some new difficulties for the insurance of information and data. To secure the information and data in association is imperative on the grounds that association nowadays inside and remotely joined with systems of IT frameworks. IT structures are inclined to dissatisfaction and security infringement because of slips and vulnerabilities. These slips and vulnerabilities can be brought on by different variables, for example, quickly creating headway, human slip, poor key particulars, poor movement schedules or censuring the threat. Likewise, framework changes, new deserts and new strikes are a huge piece of the time displayed, which helpers augmented vulnerabilities, disappointments and security infringement all through the IT structure life cycle. The business went to the confirmation that it is essentially difficult to ensure a slip free, risk free and secure IT structure in perspective of the disfigurement of the disavowing security parts, human pass or oversight, and part or supplies frustration. Totally secure IT frameworks don't exist; just those in which the holders may have changing degrees of certainty that security needs of a framework are fulfilled do. The key viewpoints identified with security of data outlining are examined in this paper. From the start, the paper recommends pertinent legitimate structure and their duties including open association obligation, and afterward it returns to present and future time, system limits, structure security in business division. At long last, two key inadequacy markers system force and structure reliance - are discovered and tantamount with EU nations. Thusly I indicated reason viewpoints and figures of security of data structures it additionally relates to the reason of estimation of transient dangers of security of frameworks for that I begin my proposal with one of the fundamental class of data security which is Cyber security.
\end{abstract}

Keyword : Cyber Security, IT

\section{INTRODUCTION}

This research report conducts analysis on security. Technology these days is going up very fast and technology has been changed the route business administered by giving online services to their customers, to secure data in to "cloud" and allowing them to get their data from smart phones and tablets. This process of securing data has given many benefits to small and large business alike. But where the benefits are there will be some risk present. Risk will be like lost of data or to protect data by any attack of security.

According to a survey which took place in 2012 about security, the graph of crimes and security attacks is gradually going up every year. 
As we talk about security it's a very huge field to do research on it. Security has many different units in a field. One can't do a research on this topic. The topic I am going to discuss in my research is cyber security. Cyber security these days is important everywhere. Where ever the data is, we need cyber security to protect and maintain our data according to our requirements

Cyber crime is far reaching, general and continually joined with different parts of the criminal natural gathering. It runs from the thievery of a specific's character to the complete interruption of a nation's Internet compromise in light of a huge trap against its masterminding and taking care of assets.

The definite focus of cybercrime divisions is on information-the information which is stored electronically for resulting and recovery reason. To get to think about that size of the cybercrime's risk, let observe on the utilization of the web. Burglary and no assurance of individual/private information through the ruptures of information and the aggregate number of cash lost. Giving somebody a data on email or over telephone/message will permit one to withdraw cash from them, e.g. by taking out cash from ledger is called "phishing". This is exceptionally normal trick on web, where the individual compelled to give individual points of interest by believing that this is genuine source.

Our regular schedule life, our national security relies on upon safe, and stable. We rely upon exceptionally propel systems to impart one another, to travel, deal with our homes, to give a help to our economy and giving administrations of government.

The assault of digital wrongdoing is drastically expanding throughout the last few years. This is occurring due to our social wellbeing depend on machine framework being protectable and tried and true. However the devices made to assault on online environment have turned into criminal's business. Hoodlums have various sorts of strategies which they use to assault on information and data.

To keep secured our information and to stop this from unapproved individual, we utilize digital security.

Cyber security is known as a data system security. Which secure your system, data, and information from obscure individual and crook? The cyber crime is expanding quick, increasing very fast. This has alarmed associations to concentrate all the more on their assurance of information and association's close to home data.

The greater part of the decently created nations concur that these sorts of digital assaults are the impressive danger to the security of any nation. (Marshall C. , 23April,2014)

\section{METHODOLOGY}

The huge goal of this paper is to make the framework security showing and advanced strike reenactment that has the limit bunch dangers, point out attack instruments, check protection parts, and survey results. To do this, we have used the pushed exhibiting and entertainment thoughts, for instance, System Entity Structure/ Model Base structure, DEVS (Discrete Event System Specification) formalism, and trial edge thought key the thing arranged S/W environment. Our system is to exhibit the refinement from others in that:

1. It helps a different leveled and specific showing environment.

2. It makes the charge level behavior of computerized attack circumstance.

3. It gives a powerful model building environment concentrated around the test packaging thought.

4. It helps the defenselessness examination of given center point on the framework.

Most IT security association theories incorporate check records which drives use to build up a degree technique; these all things considered are immaterial more than a triage method to requesting dangers. One standard procedure for 
danger visualization has been the improvement of a hazard shape, where each one core or estimation identifies with one of the three shares of risk (dangers, resources, and vulnerabilities), and the volume of the $3 \mathrm{~d}$ square relates to the measure of peril. Models have been made which attempt to strategy with peril examination in a subjective way. Mark Egan (the then CTO for Symantec) in his book The Executive Guide to Information Security displayed an amazingly clear even model which permits clients to rate threat severities into one of three game plans/ranges (low, medium and high) and after that to ordinary crosswise over shares. This agreeable triage procedure to subjective threat impact examination, however canny, is uncommon to catch framework shakiness. Albert and Doro cost added to a framework called OCTAVE which in like way uses subjective information to review peril. Others have attempted techniques that measure IT security danger examination. Beauregard joined the Value Focused Thinking (Vft) approach from general risk examination to audit the level of information affirmation inside the extension of Protection units.

The methodology used in this research report on cyber security is (QuERIES). This is designed to answer these types of questions. The theory is based on quantitative method, which is derived from games theory, computer science, economics and control theory. Preparatory analyses have confirmed the QuERIES methodology, proposing that it gives a comprehensively relevant option to team (which includes hacker who have very less or no information on system's internal security), black-hat inquiry (which involves hackers who have entered to design a system's internal security details), also other choice help procedures beforehand attempted in cyber security-related danger appraisal. QuERIES has concentrated on the issue of ensuring basic US Department of Defense (DoD) protected innovation, in which the loss of one IP duplicate is calamitous, rather than shopper IP, in which the loss of different duplicates can be endured if sufficient income can be kept up. Weapons frameworks plans, chip outlines, complex machine programming, and databases containing individual and money related data are illustrations of the previous. Computerized music, feature, customer grade programming, and electronic books are illustrations of the recent.

(Sanders, 2006)

\section{How it Works}

To outline the Queries strategy and how designers can apply it in a given programming security connection, consider the test of surveying the quality of securities connected to a specific programming resource. The securities are intended to avoid figuring out assaults in which an enemy looks to acquire discriminating IP from the product. The Queries methodology in this case includes the accompanying components.

\section{Design the Security System}

This segment develops a strike/secure financial model cast in preoccupation theoretic terms. Parameters in this model identify with target sums, for instance, the monetary estimation of the IP (the secured programming asset) to the IP holder; how much it will cost an adversary to make the IP; and the cost of getting the IP through other possible means. An exchange separating settling of the model is the protection plot (positive security game plan) of the specific protections joined with the IP asset.

\section{Design the Attack}

This component utilizes the security guide and learning of figuring out approaches to assemble an assault chart spoke to as a Partially Observable Markov Choice Process (POMDP).

\section{Evaluate Both Models}

This component evaluates parameters utilized as a part of both models by performing a controlled redgroup assault against the secured IP, then utilizing an alternate red- or dark cap 
group to lead a data market for assessing the POMDP's parameters. It then figures the POMDP's ideal strategies and uses those approaches in the assault/ensure monetary model. Once the framework has assessed both models, combining numerous inferred amounts important to hazard evaluation gets to be conceivable.

\section{QuERIES Methodology}

QuERIES methodology clients should first see their apportioning IP resources and the dangers against them through examination of their novel missions and fundamental outlines. We utilize an all around target measure of such sway's thankfulness the expense to make it. Those expenses customarily can be evaluated always utilizing changed data, yet if all else fails the change of front line structures controls a wide movement base that may beginning now have been expensed some spot else. Our documentation for the holder's expense of building up the IP is CIP. By definition, an enemy values essential IP at CIP as truly, however the headway expense to a foe, determined by $\mathrm{CD}$, could be more humble if for the most part open captivating advancement has made it more delicate to make today instead of in the later past.

Therefore the first wander of the Queries method perceives the going hand in hand with:

1. CIP: the value of the IP to the asset owner and adversary;

2. CP: the cost of protecting the IP, per unit, together with a possible amortization of the protection technology's cost over the number of units to be protected;

3. CD: the cost to the adversary of developing the IP from inception;

4. PS: the probability of stealing the unprotected IP, based, for example, on historical data for similar IP; and

5. CS: the cost of stealing the unprotected IP, based on historical data for similar IP.

The originator could assess these sums for assorted foes that have differing advancement bases from which to recreate the IP and unique limits for taking the unprotected IP (Norvig, 2002).

\section{Designing the Attack/Protect financial model:}

\begin{tabular}{|c|c|c|c|}
\hline & & \multicolumn{2}{|c|}{ You (Y) } \\
\hline & & No IP protection & IP protection \\
\hline \multicolumn{2}{|l|}{$\begin{array}{l}\text { Adversary } \\
\text { takes no action }\end{array}$} & $\begin{array}{l}\mathrm{Y}: C_{I P} \\
\mathrm{~A}: 0\end{array}$ & $\begin{array}{l}\mathrm{Y}: C_{P P}-C_{p} \\
\mathrm{~A}: 0\end{array}$ \\
\hline \multicolumn{2}{|l|}{$\begin{array}{l}\text { Adversary } \\
\text { develops IP }\end{array}$} & $\begin{array}{l}\mathrm{Y}: \mathrm{C}_{\mathbb{P}}-C_{P} \\
\mathrm{~A}: C_{\mathbb{P}}-C_{D}\end{array}$ & $\begin{array}{l}\mathrm{Y}: \mathrm{C}_{I P}-C_{P} \\
\mathrm{~A}:-C_{I P}-C_{D}\end{array}$ \\
\hline $\begin{array}{l}\text { Adversary } \\
\text { steals IP with } \\
\text { Prob }=P_{s}\end{array}$ & 产 & $\begin{array}{l}\mathrm{Y}: \mathrm{C}_{\text {lp }} \\
\mathrm{A}: \mathrm{C}_{s} \\
\mathrm{Prob}=1-P_{S}\end{array}$ & $\begin{array}{l}Y: C_{P P}-C_{P} \\
\text { A: }-C_{R} \\
\text { Prob }=1-P_{R}\end{array}$ \\
\hline $\begin{array}{l}\text { or } P_{R} \text { and } \\
\text { Cost }=C_{S} \\
\text { or } C_{A}\end{array}$ & 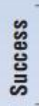 & $\begin{array}{l}\mathrm{Y}: \mathrm{C}_{I P} \\
\mathrm{~A}: C_{I P}-C_{S} \\
\mathrm{Prob}=P_{S}\end{array}$ & $\begin{array}{l}\mathrm{Y}: \mathrm{C}_{I P}-C_{P} \\
\mathrm{~A}: C_{I P}-C_{R} \\
\text { Prob }=P_{R}\end{array}$ \\
\hline & 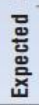 & $\begin{array}{l}\mathrm{Y}: \mathrm{C}_{I P} \\
\mathrm{~A}: P_{S} C_{I P}-C_{S}\end{array}$ & $\begin{array}{l}\mathrm{Y}: \mathrm{C}_{I P}-C_{P} \\
\mathrm{~A}: P_{R} C_{I P}-C_{R}\end{array}$ \\
\hline
\end{tabular}

Figure 1

Designing the Attack/Protect financial model

"FIGURE: In this example, the QuERIES economic model is based on a simple game-theoretic formulation. In the game, the IP owner can protect or not protect and the adversary can develop the IP abs initio or attempt to steal or reverse-engineer it. Although the case in which the adversary chooses to do nothing is listed, the definition of critical IP is that the adversary will try to obtain the IP.” (Sheyner, 2002, pp. 273-284)

The Queries attack/secure monetary model is a redirection with two persons, the hacker/attacker and the protector. Redirection speculation is a created prepare at first made to sponsorship key decision making, however now by and large used for business and financial applications as well. As Figure shows, the two major redirection moves open to the shield are guarantee or don't secure fundamental IP. Differing security headways are workable for a given IP, so eventually the safeguard has a couple of possible moves, one for each protection sort considered. In this outline, we exhibit three possible attacker moves:
1. No Action
2. Develops IP
3. Steals IP. 
By the significance of segregating IP, the enemy will endeavor to either make or take the IP. For each mix of moves by the guard and assailant, we record a verbalization for the following hardship or increment in the relating entertainment table cell. Exactly when a foe tries to take or make sense of separating IP, the probability of accomplishment is PS moreover PR, separately.

\section{Paradigm \& Methodology}

Recollecting the last destination to direct insufficiencies of security association structures, this work proposes a reason focused around stars impeccable model for mechanized security risk association. In this approach a structure is spoiled in specialists that may be utilized to accomplish targets secured by aggressors. Dangers to business are master by assailant's focuses in association and arrangement aces. To help a proactive conduct, sensors joined with security sections are broke down suitably with a model for situational consideration.

\section{RESULT AND FINDING}

This section of research report on cyber security consists of the result and findings which I have come up with in the entire research. There are many different cyber security teams that work against cyber crime and the criminal that do these types of crimes.

PC law violations have expanded in recurrence and their level of refinement has likewise propelled, a sample of such modernity is the utilization of against crime scene investigation systems as in Zeus Bonnet Crime ware toolbox that can off and on again balance computerized legal examination through its jumbling levels, in addition, unpredictability and dynamicity of the data stream in such a tool stash oblige a few sorts of a proactive examination technique or framework. The term against criminology alludes to strategies that forestall scientific instruments, examination and specialists from accomplishing their objectives. Two samples of against legal strategies are information overwriting and information covering up.

1. Prevent proof accumulation

2. Increase the examination time

3. Provide misdirecting proof that can imperil the entire examination

4. Prevent identification of advanced wrongdoing.

5. (Heard, 2011)

\section{Necessity of Cyber Security}

Data is the most profitable resource concerning chip in segment, state and nation. Regarding an individual the concerned ranges are:

1. Protecting unapproved access, revelation, alteration of the assets of the framework.

2. Security amid Online exchange, in regards to shopping, saving money line reservations and offer markets.

3. Security of record while utilizing long range informal communication destinations.

4. One key to enhance propelled security is a predominant understanding of the risk and of the vector utilized by the aggressors to evade automated shield.

5. Need to differentiated unit managing security of the association.

6. Different alliance and missions draw in interesting sorts of enemies, with varying objectives and hence oblige distinctive level of arrangement.

7. In seeing the extraordinary nature of modernized danger a connection or mission's stands up to the trading of an enemy's abilities, suggestions and focusing on exercises must be seen as concerning state and nation.

8. Securing the data contusing different key studies and their reports.

9. Suring the information reason keeping up e purposes of excitement of every single one of profits of the relationship at state level.

\section{Recent Survey issues on cyber security trends}

The following list is generated from cyber security research and survey. 


\section{Mobile Devices and Apps}

The exponential advancement of cells an exponential improvement in security risks. Every new propelled cell, tablets or other cells, opens an exchange window for a computerized attack as everyone makes a substitute weak access point to frameworks. This horrifying component is no riddle to punks who are arranged and holding up with significantly centered around malware and strikes using mobiles applications, correspondingly, the enduring issue of the lost and stolen contraptions will develop to consolidate these new advances and old ones that heretofore flew under the radar of computerized security organizing.

\section{Social Media Networking}

Creating use of internet systems administration will help individual advanced security dangers. Web organizing allocation among business is taking off thusly is the danger of ambush. In 2012, affiliation can, would like to see an augmentation in internet systems administration profiles used as channel for social building methods; to fight the risk affiliation should look past the basics of method and system change to mineral moved headways, for instance, data spillage abhorrence.

\section{Cloud Computing}

More firms will use conveyed registering. The tremendous cost saving and efficiencies of circulated registering are persuading associations to move to the cloud. A modestly formed structural designing and operational security masterminding will engage relationship to effectively manage the risk of cloud enrolling, shockingly, current study and report show that associations are putting down the basics of security due unfaltering quality concerning checking these suppliers

(Corey, 2009)
The graph below shows the ratio of distribution of attack techniques till 2013

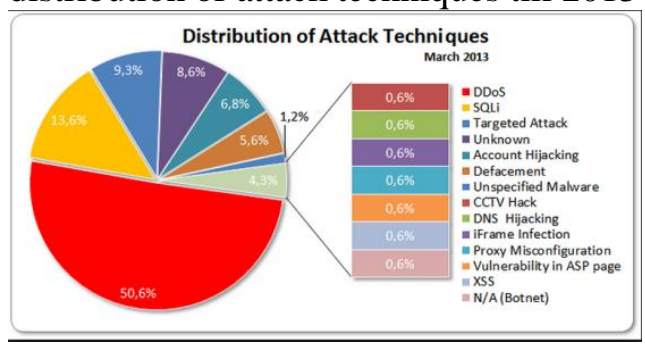

Future 2

The ratio of distribution of attack techniques till 2013

(Passeri, March 2013)

\section{PLANNING ANALYSIS AND DICUSSION}

\section{Planning}

Cyber security occurrences can incorporate denying, disturbing or taking of data on ICT frameworks. Notwithstanding the harm done to Australia's financial wellbeing and along these lines to all Australian natives, such bargains harm the notoriety of influenced associations, undermine open trust in the Australian government and superfluously devour rare cash and staff assets to constantly clean up bargains. Orgs ought to survey the estimation of data put away on their systems and apply efforts to establish safety proportionate to the danger.

Cyber security occurrences influencing government systems can be excessive to organizations, expending cash and staff assets. Specifically, offices can be affected through:

1. Service inaccessibility and lost profit

2. Damage to org notoriety and trust

3. Lost or stolen data that could damage Australia's monetary wellbeing, national security or the protection of Australian individuals

4. Staff time and expenses connected with restoring frameworks to a trusted state. 


\section{Questions for senior management to ask their IT security team}

Senior directors ought to ask the accompanying inquiries to decide how well their org is situated to react to a digital security occurrence.

\section{Reporting:}

1. What are our authoritative prerequisites and commitments for occurrence reporting?

2. Who has essential obligation regarding episode reaction in our organization?

3. Are strategies set up to give data and showing up for significant gatherings amid an occurrence? Is the IT Security Advisor acquainted with the Cyber Security Incident Reporting methodology to the CSOC?

\section{Planning and preparation}

1. Do we have a business coherence arrangement and calamity recuperation arrange and have these arrangements been consistently tried?

2. Do we have a cutting-edge and frequently tried occurrence reaction arrangement?

3. Do we have cutting-edge documentation, for example, System Security Plans and Standard Operating Procedures?

4. Do our concurrences with contracted IT benefit suppliers have plans set up for occurrence reaction?

5. Have we recognized our basic frameworks?

6. Do we have checking set up to survey our surroundings for digital security dangers?

7. Do we have forms set up to discover when an episode may have happened?

\section{Responding}

1. How effectively and rapidly would we be able to get to assets key to relieving an occurrence? (For instance, framework chiefs, specialized specialists, Internet
Service Provider, framework logs and physical framework foundation.)

2. Do we have an up and coming nightfall contact list for key staff and outer stakeholders?

3. Do we can distinguish and segregate an influenced workstation or framework?

\section{ANALYSIS}

Arranging is a methodical route for associations to focus future human capital prerequisites (interest), recognize current human capital abilities (supply), and outline and execute techniques to move the current workforce to the fancied future work state. Best in class workforce arranging is planned in a repeatable and solid design, highlighting dangers and determining needs over the long haul.

Viable workforce arranging highlights potential danger zones connected with adjusting the workforce to work necessities. They connected effectively, workforce arranging permits associations to alter assets to meet future workloads, examples of work, and principal changes in how work is expert. A workforce arranging methodology must fit the needs of a particular association and record for extraordinary qualities of the digital security calling.

Driving practice workforce arranging comprises of three parts:

1. Process: Creating a coordinated and steady method for diagnosing workforce needs and dangers. This incorporates a characterized model, information, and investigation.

2. Strategy: Giving an immediate viewable pathway in the middle of business and workforce prerequisites. This incorporates an imparted vision, administration, and constant checking or execution.

3. Infrastructure: Supporting execution of a successful and repeatable workforce arranging methodology. This incorporates a sound workforce of individuals, cooperation crosswise over levels 
and empowering engineering (Brown, 2014).

\section{DISCUSSION}

\section{Preparing for and responding to cyber security incidents}

An office ought to assess their status to react to a digital security occurrence and their capacity to give sufficient information to the CSOC if needed. This report will help an organization survey their reaction abilities and empower snappier reaction. An organization ought to keep up consciousness of the digital risk environment to aid in executing fitting alleviation methodologies. Captivating with DSD for data on digital security and the current risk environment can help orgs arrangement for digital security episode reaction. Keeping up a current security hazard administration arrangement for data security frameworks is basic. The point of the security hazard administration arrangement is to decrease the general danger to org data frameworks. The arrangement ought to include:

1. Evaluating key resources and data

2. Identifying surveyed dangers to those benefits

3. Performing an expense advantage examination for executing potential danger alleviation techniques

4. The hazard medicines executed.

Ensuring organization IT Security Advisors have decently recorded occurrence reaction techniques can spare time, cash and staff assets. This will guarantee occurrences can be contained and relieved rapidly.

Early reporting of digital security episodes to CSOC through a Cyber Security Incident Report structure (accessible from DSD's site) will empower speedier CSOC triage, moderation and regulation of the risk if needed.

\section{Firewalls}

The expression "firewall" has turned into a bland term which incorporates a range of innovations expected to give assurance from interchanges assaults on an association. Screening switches, application passages, intermediary servers, validation servers, are all cases of firewalls being used today. It is conceivable, and regularly attractive, to join these distinctive advancements as indicated by the needs of the association and their financial plan restrictions

(Vacca, 2004)

\section{CONCULSION}

According to my own exploration I have seen numerous features and read numerous articles of distinctive writers. What I personally feel is there is no $100 \%$ insurance for anything. It could be $99.99 \%$ security and there would even now $0.01 \%$ left.

Innovation is developing quickly. Furthermore consistently we wake up, we see some new changes in innovation. We exist on the planet where the innovation comes later however its need started things out. You know what I mean? It implies for e.g. on the off chance that there is another programming coming in business, it would come later yet the route how to hack it starts things out. Given me a chance to make it less demanding for you to comprehend, If any association is making another programming for them to actualize on their framework, the product will create later however the route how to assault it. You realize what I have learnt from this exploration on the off chance that you attempt to benefit anything, it will be extremely troublesome for you to figure out how to do it yet if anybody tries to do anything incorrectly, there are a few routes, there are a few alternate ways to do it, assault and Cyber security is the same thing.

As the innovation is developing, chart of assaulting is developing with it moreover. Yet as the innovation developing, they are making diverse digital security systems additionally, yet as I said there is no $100 \%$ and there won't be $100 \%$ ever. As I would like to think, somebody who says it is $100 \%$ protected 
now that gentleman does not think about this field

Organizations of both sectors private and public have seen thought time to make a huge amount of investment to make their data secure and protectable. As a result, most of them have failed while implementing cyber security strategies, the reason they failed and have went through the problems of security is applying strategy without using useful guidance from a correct, harsh, quantitative risk-assessment and mitigation or cure methodology. Very simple and basic questions for e.g. how much to invest for security, which security will have a strong impact on organization. What is the improvement level in cyber security now days difficult to answer?

The clear center of cybercrime divisions is on data the data which is put away electronically for coming about and recuperation reason. To get to consider that size of the cybercrime's danger, let see on the usage of the web. Thievery and no confirmation of individual/private data through the bursts of data and the total number of money lost. Giving some person information on email or over phone/message will allow one to withdraw money from them, e.g. by taking out money from record is called "phishing". This is outstandingly ordinary trap on web, where the individual urged to give individual purposes of enthusiasm by accepting that this is certified source.

\section{REFERENCES:}

Brown, T. (2014). The Importance of Cyber Security Within Your Organization.

Corey, J. T. (2009). Cyber Security-

Challenges for Society.

Heard, N. (2011). The Proactive and

Reactive Digital Forensics Investigation

Process.

Marshall, C. (23April,2014). Building

Enterprise Solutions to 8 Major

Cybersecurity Problems.
Marshall, C. (23April,2014). Building

Enterprise Solutions to 8 Major

Cybersecurity Problems.

Norvig, S. R. (2002). Artificial

Intelligence: A Modern Approach, 2nd

ed., Prentice Hall.

Passeri, P. (March 2013). Cyber Attacks

Statistics.

Pathak, C. T. (2013). Review of National

Cyber Security Policy.

Sanders, W. (2006). Measuring Critical

Infrastructure Security.

Sheyner, e. (2002, pp. 273-284).

"Automated Generation and Analysis of Attack Graphs.

Vacca, J. R. (2004). Internet Security

Primer. 